\title{
From Cinematographic to Hypertext Narrative
}

\author{
Clara Mancini \\ Knowledge Media Institute \\ The Open University, Milton Keynes, MK7 6AA, UK \\ E-mail: C.Mancini@open.ac.uk
}

\begin{abstract}
This paper argues that cinematographic language may provide insights into the construction of narrative coherence in hypertext. Brief examples of cinematic representation models are mapped onto the hypertext domain.
\end{abstract}

KEYWORDS: cinematography, juxtaposition, narrative.

\section{INTRODUCTION}

In the history of communication systems, paradigms borrowed from old media have always mediated the passage to new ones, regardless of their technical differences. From paint to photography, from theatre to cinema, a period of adapting old forms helped emerging media to find their own aesthetics according to own distinctive technical characteristics. Currently, we see literary theory being applied to hypertext [7] and hypertext being used in video [12]. Here, we look at what cinematic language may suggest about hypertext discourse models [9].

\section{HOW CINEMA BUILDS MEANING}

The cinematic minimal linguistic unit is the shot (the frame being the minimal technical unit), which, in semiotic terms, is the equivalent of a linguistic enunciation (i.e. the simplest shot is already a rich semantic unit). By juxtaposition, such "self standing fragments" generate the film discourse before the viewer's eyes [11]. Because of its iconic nature, the cinematographic language expresses concepts by representing events, through the sequence of shots. However, the cognitive connection of shots requires a specific competence on the part of the user, there being no grammatical devices linking them in a cohesive discourse. Coherence and meaning are not dictated to the user: she has to infer them by linking shots on the basis of their semantic content [3].

With the discovery of montage, the presentation of fragments of reality became a representation of something else and cinema as a language was born. During half a century of evolution, the cinematic medium developed its own discourse apparatus, in the form of representational and narrative models to construct logical cause-effect sequences

Permission to make digital or hard copies of all or part of this work for personal or classroom use is granted without fee provided that copies are not made or distributed for profit or commercial advantage and that copies bear this notice and the full citation on the first page. To copy otherwise, or republish, to post on servers or to redistribute to lists, requires prior specific permission and/or a fee.

Hypertext 2000, San Antonio, TX.

Copyright 2000 ACM 1-58113-227-1/00/0005 ...\$5.00 of actions in time-space coherent worlds. However, because the medium is based on the "displaying act" and on the juxtaposition of visual units, these representative models can easily integrate the analogical to the logical paradigm. Both logical and analogical juxtapositions have a "signifying potentiality"; but especially the analogical ones generate meaning in the same way two chemical agents generate a reaction. Eisenstein used to call them intellectual montage (as distinguished from the harmonic one). In his movie Strike, he juxtaposes a shot showing the strikers led away by the regime police with a shot showing a herd of cattle driven to the slaughterhouse: the connection has a strong predicative power, the latter shot (inserted into the world of factory workers) becoming the interpretative key of the whole sequence [3].

\section{COHERENCE IN CINEMA AND IN HYPERTEXT}

Cinema and hypertext have several features in common. Like cinema, hypertext is a visual medium, the computer screen being a visual field where narrative space and time arise from a temporal articulation of spatial components [8]. Like cinema's shots, hypertext components constitute "self standing cores" of content, whose connection effects and expresses a strong semantic relationship. As hypertext fragments are not physically contiguous elements but rather untied units, their temporal or spatial contiguity, due to the activation of a link, actually constitutes a juxtaposition, a generative combination, a connection creating meaning this may be the a key parallel between the two media's narrative models.

In cinematographic discourse the chain of fragments is made by the author, while in hypertext discourse this chain is co-produced by the author and the user. Nevertheless, the user is similarly committed in hypertext and film engagement, as in both cases she has to re-construct a coherent semantic world, starting from fragments. In literary discourse, coherence and organization (which depend on text spans' semantic content) are supported by linguistic devices and continuity [5, 4]. However, in cinema there are no linguistic devices, while in hypertext there is not continuity: in both cases, discourse coherence and organization can rely on the particular effect of semantic units' juxtaposition.

As the cinematographic message technically is a fixed temporal sequence of shots, the narrative structures cannot be disintegrated without consequences. By disintegrating the usual narrative models, to make the user cognitively more interactive, most contemporary directors finally eroded the film discourse itself: because the cinematographic medium 
isn't technically interactive, its discourse needs the order supplied by conventional narrative structures. However, with the electronic medium it's different. The hypertext user is not abandoned in front of a screen emitting "dream" light and filling her visual field in a fixed sequence. Taking her time, she is individually committed to a space whose elements are revealed on searching, as she explores this space and concretely constructs her discourse. In hypertext, the loosening of predefined structures is possible as the user becomes herself the character of a discovery journey. The price of this gain in interactivity is the loss of continuity guaranteed by traditional media and the risk that both author and user "miss each other". Cinematic language may provide clues for resolving this tradeoff.

\section{FROM CINEMA TO HYPERTEXT LANGUAGE}

Christian Metz proposes a grande syntagmatique of cinema [11] a set of eight basic rhetoric models by which linguistic units are created and connected to construct space and time. Let us map just a couple of these figures onto the domain of hypertext argumentation, this being particularly vulnerable to non-linearity, and the focus of growing interest in hypertext theory $[6,2]$. Consider the so called alternate syntagm, where two series of shots show the development of two simultaneous actions converging towards a unique final shot. In hypertext, this could translate into the display on screen of two corresponding converging series of fragments containing the elements of apparently different theses, to show that they indeed converge, as concluded in a common fragment for both the series. A second example is the dialectic shot/counter-shot by which cinematographic language builds the relation between a character and its spatial context. If a shot shows a character's eyes and the following shot shows a green landscape, then the user interprets the second shot as the character's view; but if in a third shot, a camera zoom out from the eyes shows the character to be in a snowy landscape, then the user realizes that there is a conflict between the two views and looks for another interpretation. In hypertext argumentation, this model could be used to display the incompatibility of an argument with a concept: a fragment containing the concept could be juxtaposed on the screen with a fragment containing the elements of argumentation, whilst a third fragment (connected to the first) could give information about the concept's context in order to emphasize the incompatibility of that context with the available argument. As a third example, building on spatial hypertext [10], an image could be juxtaposed with an argumentative hypertext structure just like the autonomous shot in Strike.

In his classification of hypertext rhetorical patterns, Bernstein [1] identifies a pattern called montage (significantly the only one he does not represent as a path): "distinct writing spaces appear[ing] simultaneously, reinforcing each other while retaining their separate identities". From a cinematographic perspective, having synchronic and diachronic dimensions, montage is the essence of a visual medium language. The technical characteristics of hypertext make possible even more flexible uses of it to present any kind of pattern. If fragments appearing on the screen, in logical or analogical juxtapositions, are complementary to the composition of a "discourse shape", then the user may want to complete herself the "picture", looking for missing fragments.

\section{CONCLUSIONS}

We are working on the hypothesis that a mapping between cinematographic rhetoric models and the hypertext medium can help the development of hypertext narrative models. Just as the syntagmatic of cinema was developed to shape story and time space, a "syntagmatic of hypertext" could be developed. Can we build on the widespread literacy that cinema has already established?

\section{ACKNOWLEDGEMENTS}

The author thanks Simon Buckingham Shum for the insightful discussions and the very helpful comments.

\section{REFERENCES}

1. Bernstein, M. Patterns of Hypertext. Proceedings of Hypertext '98, pp. 21-29.

2. Carter, L.M. Arguments in Hypertext: Order and Structure in Non-Sequential Essays. PhD Thesis, University of Texas at Austin, December 1997.

3. Cuccu, L., Sainati, A. (edited by) Il discorso del film. Visione, narrazione, enunciazione. Napoli, Edizioni Scientifiche Italiane, 1988.

4. Genette, G. Figure III. Paris, Éditions du Seuil, 1972

5. Knott, A., Sanders, T. The Classification of Coherence Relations and their Linguistic Markers: An Exploration of Two Languages. Journal of Pragmatics, vol. 30, 1998, pp. 135-175.

6. Kolb, D. Scholarly Hypertext: Self-Represented Complexity. in Proceedings of Hypertext 97, pp 29-37

7. Landow, G. Hypertext: The Convergence of Contemporary Critical Theory and Technology. Baltimore, Johnsons Hopkins University Press, 1992.

8. Luesebrink, M.C. The Moment in Hypertext: A brief Lexicon of Time. Proceedings of Hypertext '98, pp. 106-112.

9. Miles, A. Cinematic Paradigms for Hypertext. Continuum: Journal of Media \& Cultural Studies, vol. 13, 1999, pp. 217-225.

10. Marshall, C.C. Shipman, F.M. Spatial Hypertext: Designing for Change. Communications of the ACM, vol. 38, 1995, pp. 88-97.

11. Metz, Ch. Essais sur la signification au cinéma·I. Éditions Klincksieck, 1968.

12. Sawhney, N., Balcom, D., Smith, I. HyperCafe: Narrative and Aesthetic Properties of Hypervideo. Proceedings of Hypertext '96, pp. 1-10. 